The University of San Francisco

USF Scholarship: a digital repository @ Gleeson Library |

Geschke Center

January 2011

\title{
Making a Science of Service Systems Practical: Seeking Usefulness and Understandability while Avoiding Unnecessary Assumptions and Restrictions
}

Steven Alter

University of San Francisco, alter@usfca.edu

Follow this and additional works at: http://repository.usfca.edu/at

Part of the Business Administration, Management, and Operations Commons, Management Information Systems Commons, and the Technology and Innovation Commons

\section{Recommended Citation}

Alter, Steven, "Making a Science of Service Systems Practical: Seeking Usefulness and Understandability while Avoiding Unnecessary Assumptions and Restrictions" (2011). Business Analytics and Information Systems. Paper 27.

http://repository.usfca.edu/at/27

This is brought to you for free and open access by the School of Management at USF Scholarship: a digital repository @ Gleeson Library | Geschke Center. It has been accepted for inclusion in Business Analytics and Information Systems by an authorized administrator of USF Scholarship: a digital repository@Gleeson Library| Geschke Center. For more information, please contact repository@usfca.edu. 


\title{
Making a Science of Service Systems Practical: Seeking Usefulness and Understandability while Avoiding Unnecessary Assumptions and Restrictions
}

Steven Alter, University of San Francisco, alter@usfca.edu

\begin{abstract}
This book's theme is "The Science of Service Systems," yet there is substantial question about whether the definition and nature of service systems have been articulated adequately. This paper examines definitions of service and service system that could frame or otherwise influence future developments in service science and could have implications for what should and should not be included within service science. It argues that the initial development of service science should use straightforward definitions that are understandable, useful, broadly applicable, and teachable. It proposes a definition of service system that is different from the definition proposed in this book's Call for Chapters and in the 2008 White Paper produced by a service innovation symposium attended by many leaders in the effort to create service science. In comparison with that definition, this paper's alternative definition is more understandable, useful, broadly applicable, and teachable.
\end{abstract}

Keywords: service science, service systems, service, work system, work system framework,

\section{Desired Characteristics of Basic Concepts}

Ideally, the evolution of service science should generate intellectually rigorous concepts that are directly relevant to practice. Practical foundational concepts should have the following characteristics:

- Understandability: The foundational concepts at the core of service science should be readily understandable by typical business professionals, not just by Ph.D.'s and technical experts.

- Usefulness: The foundational concepts should lead to description, analysis, and design methods that are readily useable by most managers and executives. Support of sophisticated descriptions and analysis by technical experts is an important second order issue.

- Broad applicability: Foundational concepts should cover all situations that typical business professionals would normally view as service.

- Teachability: Those concepts should be teachable to different audiences at different levels of intellectual sophistication.

This paper focuses on two concepts: service and service system. It argues that early leaders in service science seem to favor definitions that have important shortcomings and that might be replaced by more beneficial definitions. In particular, this paper argues that the currently favored conceptualization of service system and related ideas is too sophisticated to be useful to typical MBA students and business professionals. That type of issue would not be a problem in the physical or biological sciences, where the future development of physics and biology does not depend on whether most people understand Maxwell's Equations, quantum mechanics, cosmology, or the mechanics of DNA and RNA. It is a problem, however, if the goal of service science is to influence the practice of business.

This chapter proceeds as follows. First, it looks at alternative definitions of service. It identifies three groups of definitions, proposes that the third group comes closest to satisfying the above criteria, and suggests a particular definition that is simple and general. Next, it compares two definitions of service systems, "service systems as work systems" and "service systems as complementary components of economic exchange." It shows why the above criteria are better satisfied by the first definition than the second.

\section{What Are Services?}

Many discussions of services try to define services without giving many examples, thereby skewing the discussion to the author's preferred or unstated examples and sometimes generalizing from one or several types of services. Instead, we start with a set of representative situations that most business professionals would view as services. (See Table 1)

(c) Steven Alter, 2011. Subsequently edited and published as pp. 61-72 in H. Demirkan, J.C. Spohrer, and V. Krishna, The Science of Service Systems, Springer, 2011 
Table 1: Common examples of services

\begin{tabular}{|c|c|}
\hline 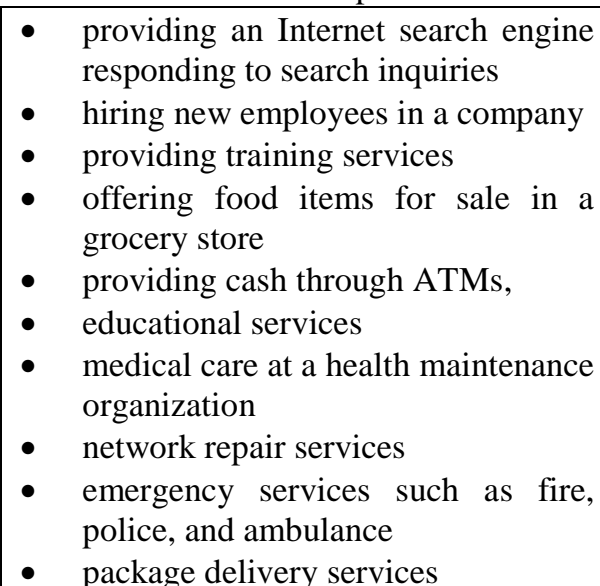 & $\begin{array}{ll}\text { - } & \text { janitorial services in office buildings } \\
\text { - } & \text { download services for books and } \\
\text { - } & \text { films } \\
\text { - } & \text { architectural services } \\
\text { - } & \text { consulting services } \\
\text { - } & \text { entertainment services } \\
\text { - } & \text { answering customer inquiries at an } \\
\text { - } & \text { off-shore call center } \\
\text { - } & \text { werforming back-office accounting off } \\
\text { - } & \text { legal services } \\
\text { - } & \text { garbage collection services location } \\
& \text { telemmication services }\end{array}$ \\
\hline
\end{tabular}

A good definition of service should fit each of the situations in Table 1. We will look briefly at definitions that fall under three categories:

- Services as value creating activities that have certain characteristics

- Services as value creating activities that involve co-production by providers and consumers

- Services as any organized activities performed for the benefit of others

Category \#1: value creating activities that have certain characteristics. Examples of definitions in this group include:

1. "Any act or performance that one party can offer to another that is essentially intangible and does not result in the ownership of anything." (Kotler and Keller 2006)

2. "A provider-client interaction that creates and captures value" (IBM Research 2009).

3. "A simultaneous or near-simultaneous exchange of production and consumption, transformation in the experience and value that customers receive from engagement with providers, and intangibility in that goods are not exchanged." (Rai and Sambamurthy 2006)

A typical problem with defining services in terms of specific characteristics is that many services lack those characteristics. For example, the service of custom-designing and programming complex software often involves a project that absorbs months of time (inconsistent with \#3), involves substantial efforts unrelated to customer interactions or experiences (inconsistent with \#2), produces tangible things, such as printed documentation (inconsistent with \#1), and results in the ownership of something (inconsistent with \#1). Thus, the service of custom-designing and programming complex software does not fit several typical definitions of service. Other relevant examples in Table 1 include package delivery services that move tangible packages, architectural services that result in the ownership of architectural plans, garbage collection services that involve minimal provider-client interaction, and legal services that produce contracts that are used for many years, and hence are not consumed as produced. Along these lines, Vargo and Lusch (2004b) argue that four prototypical characteristics often believed to distinguish services from goods - intangibility, inseparability, heterogeneity, and perishability - "(a) do not distinguish services from goods, (b) only have meaning from a manufacturing perspective, and (c) imply inappropriate normative strategies."

Category \#2: activities involving co-production of value by providers and consumers. Examples of definitions in this group include:

- A time-perishable, intangible experience performed for a customer acting in the role of a coproducer (Fitzsimmons and Fitzsimmons 2006).

- A process in which "the customer provides significant inputs into the production process." (Sampson and Froehle 2006)

- "The customer is always a co-producer." This is foundational premise \#6 from Vargo and Lusch (2004a). Their definition of service is in the next category (below). 
The difficulty with defining service in terms of co-production is that an increment from zero co-production to a little bit of co-production to a slightly larger amount of co-production often does not change the essential nature of the activities or of the value that is being produced. Most of the examples in Table 1 involve at least a bit of coproduction, such as making a request that initiates a process, or making one or more choices that influence the production process. Even the output of highly automated production lines often involves at least some input from the customer, thereby blurring the distinction between product and service.

Category \#3: activities performed for the benefit of others. Examples of definitions in this group include:

- "A change in the condition of a person, or a good belonging to some economic entity, brought about as a result of some other economic entity, with the approval of the first person or economic entity" (Hill 1977).

- "Capabilities or competencies that one person, organization, enterprise, or system provides for another" (Vargo and Lusch 2004a).

Although the assumption about customer approval is contradicted in many service situations (e.g., emergency services where the customer cannot provide approval, teaching of unwilling students, and so on), definitions in this category are less restrictive and less encumbered by occasionally irrelevant characteristics such as intangibility and simultaneity. We adopt an even simpler, dictionary-like definition of service:

Services are acts performed for someone else, including the provision of resources that someone else will use. (Alter 2008b)

This definition of service encompasses a wide range of categories such as:

- services for external customers and for internal customers,

- automated, IT-reliant, and non-automated services,

- customized, semi-customized, and non-customized services,

- personal and impersonal services,

- repetitive and non-repetitive services,

- long-term and short-term services,

- $\quad$ services with varying degrees of self-service responsibilities.

The phrase about provision of resources for someone else is included to accommodate the shift toward supporting self-service activities. The definition can be extended into the realm of service computing by substituting "another entity" for "someone else." Services in that realm can be viewed as acts performed by one entity for a different entity, including the provision of resources that a different entity will use.

In effect, this definition assumes that every purposeful action performed for the benefit of someone else is a service, an interpretation consistent with discussions that have continued in marketing for over 40 years. For example, Leavitt (1960) noted, "People don't buy a quarter-inch drill. They buy a quarter-inch hole. You've got to study the hole, not the drill. The drill is just a solution for it." More recently, Vargo and Lusch (2004a) extended that train of thought in proposing that "service-dominant logic" should replace "goods-dominant logic" as the basis of economic thought. They argue that value to the customer is the primary issue, and that delivery through goods versus services is secondary. One of eight foundational premises in their 2004 summary of service-dominant logic is that "goods are distribution mechanisms for service provision." Thus, distinctions between products and services may not be fundamental for understanding how value is delivered. If a service is an act performed for someone else, then the production of physical things can be viewed as services.

With our definition of service, just about any business activity is a service because it involves purposeful action performed for the benefit of someone else. Focus on services is still useful, however, because it encourages the use of service metaphors when thinking about almost any system in a business. Of special value are the numerous service-related design dimensions that are potentially important but often overlooked when trying to design or evaluate systems in organizations. This brings us to the discussion of service systems.

\section{What Are Service Systems?}

The literature contains two basic views of service systems:

- Service systems as work systems that produce services.

(c) Steven Alter, 2011. Subsequently edited and published as pp. 61-72 in H. Demirkan, J.C. Spohrer, and V. Krishna, The Science of Service Systems, Springer, 2011 
- $\quad$ Service systems as complementary components of economic exchange.

The first view focuses on service production processes (which involve varying degrees of co-production by providers and customers) and on whatever those production processes produce for customers. Both the initial description of the situation and the subsequent analysis emphasize how the service is produced, how well it is produced, and how it might be improved. The specifics of the description and analysis are consistent with lean solutions (Womack and Jones 2005), Six Sigma, and other methods used in disciplines such as marketing, operations management, and information systems.

In contrast, the second view of service systems starts with economic exchange. It views providers and customers as service systems that provide services for each other. For example, a grocery store is a provider service system that obtains and displays food for sale; customers are customer service systems that perform the complementary service of paying the retailer; they also provide other forms of cooperation, such as acting appropriately in the store.

We look at each of these approaches in turn, emphasizing topics related to deciding which of these two starting points satisfies previously mentioned criteria such as understandability and usefulness. Note, however, that neither view excludes the other. For example, someone starting with the first approach has total freedom to consider economic exchange. In fact, incentives are an important part of the description and analysis related to work system participants and customers. Similarly, someone starting with the second approach has total freedom to analyze the provider service system and customer service system as work systems on their own right.

The following discussion reflects a clear bias toward the first definition because it more directly satisfies the criteria mentioned at the outset. Specifically, it is more effective for helping business professionals produce practical descriptions, analyses, and recommendations for improvement in service situations such as those listed in Table 1.

Definition \#1: service systems as work systems that produce services. A service system is a work system that produces services for customers. A work system is a system in which human participants and/or machines perform work using information, technology, and other resources to produce products and/or services for internal or external customers. (Alter 2003, 2006a, 2008a). All of the services in Table 1 can be described as work systems.

The work system framework (Alter 2003, 2006a, 2008a, 2008b) identifies nine elements that are the basis for describing and analyzing any work system in an organization. (See Figure 1) Even a rudimentary understanding of a work system (or service system) requires awareness of each of the nine elements in the framework. These elements are strikingly similar to the elements listed by Karni and Kamer (2007) in their "taxonomic definition of a work system." The framework covers situations that might or might not have a tightly defined business process and might or might not be IT-intensive. It can be used to describe work systems in general, information systems, supply chains, and projects.

The location of the customer at the top of the framework's triangular representation is totally consistent with our definition of service (acts performed for someone else). It encourages including a service mindset in both description and analysis by illustrating the incompleteness of focusing totally on the internal operation of the work system. Also, the arrows in the framework show that changes in customer needs lead to desired changes in the form, cost, or quality of products and services, which in turn lead to desired changes in the form or performance of processes and activities. Following arrows from the other direction, changes related to participants, information, and technology can be evaluated based on their impact on both internal efficiency and customer satisfaction. 


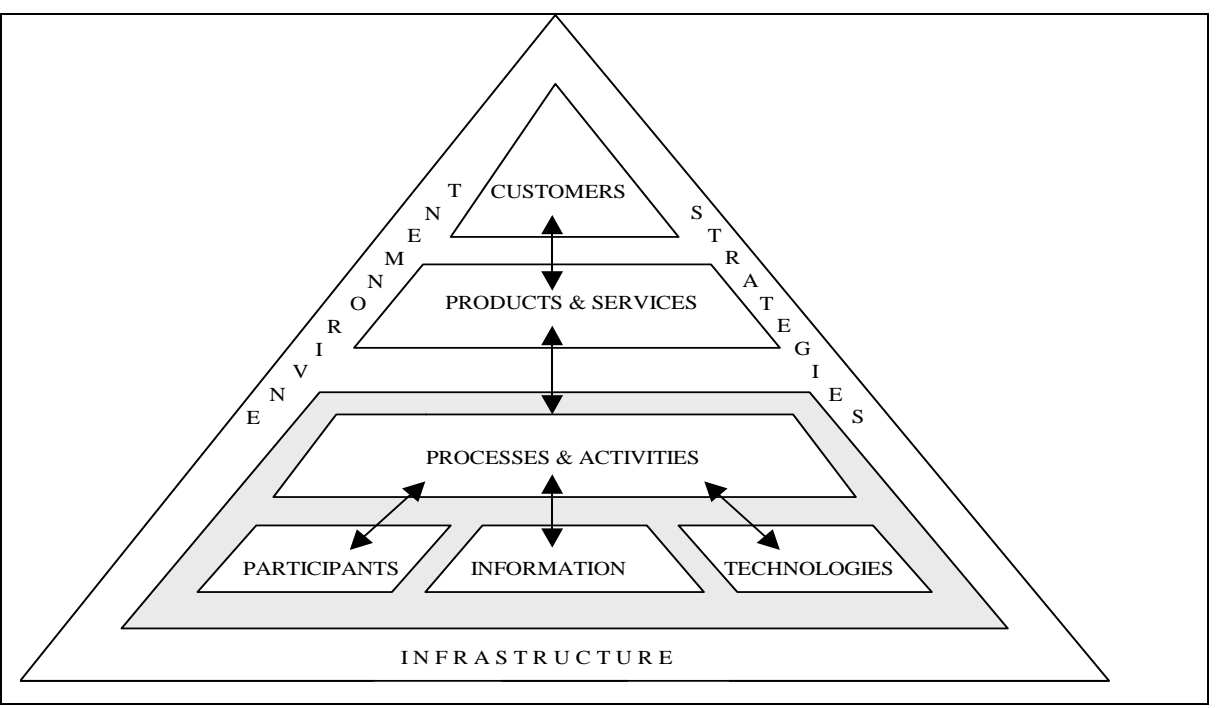

Figure 1: The work system framework (Alter 2006a), slightly updated

The bilateral form of the service value chain framework (Alter 2008a) is based on the co-production of value by providers and customers. (The framework is not shown here due to space limitations.) That framework, which can also be applied readily to describe or analyze each of the services in Table 1, augments the work system framework by incorporating typical categories of service activities and responsibilities, such as negotiating commitments, performing set-up, handling service requests, fulfilling service requests, and performing follow-up. Other aspects of the framework represent important service design issues such as the governance of service instances by service level agreements, the form and frequency of service encounters, the distinction between front-stage vs. back-stage activities, and the importance of value capture by both customer and provider.

In addition to providing useful and distinct component views of service systems, both the work system framework and the service value chain framework help in identifying important design dimensions that can be used to describe and compare service systems. For example, Alter (2006a) discusses business process design dimensions such as degree of structure, range of involvement, level of integration, complexity, rhythm (frequency) and degree of automation, among others. Focusing on these dimensions when evaluating, analyzing, or designing a work system helps in addressing big picture issues before plunging into details. Similar design dimensions related to the service value chain framework include the balance between provider and customer responsibilities, the relative amount of effort to be devoted to negotiating commitments, the relative importance of customer encounters, and the relative prominence of front-stage vs. back-stage activities.

Definition \#2: service systems as complementary components of economic exchange. In contrast to viewing service systems as work systems, the concept of service system in recent publications of leading proponents of service science (e.g., Spohrer et al. 2007, Spohrer et al. 2008, IfM and IBM 2008, Springer 2008) treats service systems as complementary components of economic exchange. For example, the definition of service system on the first page of this book's Call for Chapters (Springer 2008) says that service "derives from the interactions of entities known as service systems. Service systems at multiple scales of organizations, from individual people to businesses and nations, chain together into globally integrated service networks of multiple types... [B2B, B2C, etc.]" A footnote at the bottom of the first page says "Service systems are dynamic value co-creation configurations of people, technology, organizations, and shared information (such as language, laws, measures, models, etc.), connected internally and externally by value propositions, with governance mechanisms for dispute resolution." (Spohrer et al. 2007). In other words:

- Service is produced by the interaction of service systems (i.e., an individual service system does not produce services).

- $\quad$ Service systems are dynamic.

- Service systems are shared co-creation configurations of people, technology, organizations, and shared information.

- $\quad$ Service systems range from individual people to businesses and nations.

(c) Steven Alter, 2011. Subsequently edited and published as pp. 61-72 in H. Demirkan, J.C. Spohrer, and V. Krishna, The Science of Service Systems, Springer, 2011 
- Service systems are connected internally and externally by value propositions.

- Service systems have governance mechanisms for dispute resolution.

A subsequent White Paper on service innovation generated by a Cambridge UK symposium of service science leaders (IfM and IBM 2008) is largely consistent with the above view. Its glossary of terms adds the following:

- Service systems ... "can create and deliver service while balancing risk-taking and value-cocreation." (p. 18)

- "Service systems are complex adaptive systems." (p. 18)

- A customer service system is "a service system from the viewpoint of a customer or consumer. A customer service system searches provider value propositions looking for win-win value-cocreation opportunities." (p. 16)

- A provider service system is "a service system from the viewpoint of a provider. A provider service system aims to meet the customer's needs better than competing alternatives consistently and profitably (in business context) or sustainably (in non-business context). Provider service systems seek deep knowledge of customer service systems ... to improve existing, and create new, value propositions.” (p. 16)

- A value proposition is "a specific package of benefits and solutions that a service system intends to offer and deliver to others. ... Value proposition emphasizes key points of difference in comparison to competing alternatives." (p. 19)

\section{Is the second definition of service system practical?}

While recognizing that testing is required to evaluate a definition's practicality, it is nonetheless possible to find relevant hints about practicality in prior uses of related ideas and in direct implications of the definitions.

The practicality of the first definition is supported by extensive experience. Various versions appeared in a series of information system textbooks culminating in Alter (2002) and in term paper assignments requiring the application of related analysis methods. In an attempt to continue developing the work system approach over many years, the author collected and evaluated over 400 term papers representing system analysis efforts by teams of undergraduate, MBA, and Executive MBA students at a typical university, i.e., not at elite universities like MIT or Stanford. Most of the MBA and Executive MBA students were employed and are a reasonable proxy for early career business professionals. A paper on the results through 2005 was published several years ago (Alter 2006b). Elsewhere, Petkov and Petkova (2006) demonstrated the usefulness of the work system framework by comparing grades of students who did and did not learn about the framework before trying to interpret the same ERP case study. More recently, Truex and Alter (2010) describe how 75 advanced MBA students at Georgia State University applied a work system analysis template to produce preliminary analyses of real world systems in their own organizations, and to produce recommendations for improving those work systems, most of which produced services. Results to date indicate that typical employed MBA students can use the work system approach to attain a basic understanding of service systems such as those in Table 1.

The second definition was published several years ago. The author is not aware of any attempts to test whether the second definition can be used effectively by typical students or business professionals. However, even at this stage, it seems likely that typical MBA and EMBA students and typical business professionals would be hard pressed to apply or even understand the relevance of certain aspects of the service system characteristics associated with the second definition. That conclusion is based on examination of the ideas (below) and on experience in teaching related courses and grading hundreds of papers written by employed MBA students. Here are some of the relevant issues:

Issue \#1: Assumption that service is created by the interaction of provider service systems and customer service systems. Most MBA students would be confused by this assumption. It seems highly doubtful that they would find it natural to think of themselves as customer service systems when they buy something at a store or obtain information from a search engine. They would find it much more natural to think about service systems as single systems that produce (or co-produce) services for customers who may or may not be involved extensively in the service process. It is not apparent why one would have to describe or analyze customers as service systems in order to understand or analyze any of the services listed in Table 1. Seeing services as the interaction of service systems is especially awkward with services such as medical care, in which the direct customer, the recipient of the medical care, may be completely uninvolved with the economic exchange that pays for the medical services. Yes, 
the customer or someone else needs to pay, but it is not apparent why calling a paying customer a service system is always beneficial when trying to understand how and how well medical services are provided and used.

Issue \#2: Individuals, businesses, and nations all viewed as service systems. Most MBA students would have difficulty seeing how individuals, businesses, and nations could all be viewed usefully as instances of service systems. Although all three of these can be viewed as legal entities with rights and responsibilities, it is not clear what would be the teachable common denominator for describing or analyzing service systems across that rangefrom one person to over a billion. Characteristics and activities of individual people usually do not appear on the same scale as characteristics and aggregate activities of businesses and nations.

Issue \#3: Unnecessary restrictions. A fundamental view of service systems should apply to the complete spectrum of services: services for external customers and for internal customers; automated, IT-reliant, and non-automated services; customized, semi-customized, and non-customized services; personal and impersonal services; repetitive and non-repetitive services; long-term and short-term services; and services with varying degrees of self-service responsibilities. Contrary to the previously mentioned definition of service system in IfM and IBM (2008), many service systems are not dynamic or complex, many do not require consistency or strive for profit, and many serve both internal and external customers. Most business professionals who have had difficulties related to services such as airline travel and health insurance would question whether "a customer service system searches provider value propositions looking for win-win value-cocreation opportunities." (IfM and IBM 2008, p. 16)

Issue \#4. Unnecessary complexity. Defining service systems as "dynamic value co-creation configurations" that are "connected internally and externally by value propositions" introduces terms that most MBA students and business professionals would find difficult to understand and use. For example, assume that the service is public transportation, package delivery, or reimbursement of travel expenses. What is the meaning of dynamic configuration in those contexts? Are some configurations more dynamic than others? In such contexts typical MBA students and business professionals would have difficulty explaining how the service systems are "connected internally and externally by value propositions." They would have difficulty viewing most of the service systems in Table 1 as complex adaptive systems. (What would that tell them?) Also, most would recognize that services need to be managed but would have difficulty articulating why "governance mechanisms for dispute resolution" are first order elements of most of the services in Table 1. For example, governance mechanisms for dispute resolution would not be first order topics when thinking about how to improve educational services, telecommunications services, janitorial services in office buildings, and many of the other services in Table 1.

Issue \#5. Inherent characteristics vs. design dimensions. Service science should avoid confusions between inherent characteristics of all services versus service dimensions that call for design decisions. For example, IfM and IBM (2008, p. 16) says that service systems "aim to consistently and profitably meet the customer's needs." It is more accurate to say that consistency is a design dimension. Consistency is very important for some service systems and unimportant for others. A service system designer should decide the extent to which consistency should be encouraged or enforced. A similar observation about inherent characteristics of service versus dimensions of service applies to other proposed characteristics such as dynamic, complex, adaptive, connected internally and externally, and win-win. Likewise, profitability is important in some service situations but not in many others, such as those provided by government and non-profits.

\section{Conclusion}

An important part of the initial development of service science has involved the search for basic definitions and concepts that bring the potential of organizing and focusing this newly emerging field. Service science needs a foundation of concepts that satisfy criteria such as understandability, usefulness, broad applicability, and teachability.

This paper has argued that a currently favored conceptualization of service system is too sophisticated to be useful to typical MBA students and business professionals. That type of issue would not be a problem in the physical or biological sciences, but is a problem for service science since the goal of influencing the practice of business is more important than the goal of allowing Ph.D. researchers to philosophize about abstractions. 
Implications for practice. The development of service science might have important impacts on practice by providing organized sets of ideas that can be used to describe, analyze, and improve service systems. Those impacts depend on the existence of a conceptual basis that is genuinely usable by typical business and IT professionals. Managers and other decision makers are unlikely to embrace service science fully until its basic ideas are clear, straightforward, and usable by their business peers in practical situations.

Implications for research. This paper's discussion of the work system approach to service systems demonstrates that the IfM and IBM (2008) approach is not the only alternative for defining service, service system, and other relevant terms. Ideally, proponents of that approach should test its understandability, usefulness, breadth of applicability, and teachability. This can be done by asking business professionals or MBA students to use that approach to analyze a broad range of service examples. Better yet, research subjects could try to apply that approach to analyzing and making recommendations about real world situations, much as has been done in the development of the work system approach. Ideally, both approaches might be compared to additional alternatives and then evaluated by observing how effectively business professionals, students, and Ph.D. researchers can apply each approach fruitfully to the complete gamut of services.

\section{References}

Alter, S. (2002). Information Systems: The Foundation of E-Business, $4^{\text {th }}$ ed., Prentice Hall: Upper Saddle River, NJ.

Alter, S. (2003). 18 Reasons why IT-Reliant Work Systems Should Replace the IT Artifact as the Core Subject Matter of the IS Field. Communications of the Association for Information Systems, 12(23), 365-394.

Alter, S. (2006a). The Work System Method: Connecting People, Processes, and IT for Business Results. Larkspur, CA: Work System Press.

Alter, S. (2006b). Pitfalls in Analyzing Systems in Organizations. Journal of Information System Education, 17(3), Fall 2006, pp. 295-302.

Alter, S. (2008a). Service System Fundamentals: Work System, Value Chain, and Life Cycle. IBM Systems Journal, 47(1) 71-85.

Alter, S. (2008b). Service System Innovation. Proceedings of IFIP Working Group 8.2 Conference on IT and Change in the Service Economy, Toronto, Canada, August 2008.

Fitzsimmons, J.A. \& Fitzsimmons, M.J., (2006). Service Management, $5^{\text {th }}$ ed. New York, NY: McGraw-Hill.

Hill, T.P. (1977). On goods and services. The Review of Income and Wealth, 23, 315-338.

IBM Research (2009). Services Science, Management and Engineering. http://researchweb.watson.ibm.com/ssme/services.shtml. Accessed 19 Sept. 2009.

IfM \& IBM. (2008). Succeeding through Service Innovation: A Service Perspective for Education, Research, Business and Government. Cambridge, United Kingdom: University of Cambridge Institute for Manufacturing. ISBN: 978-1-902546-65-0. http://www.ifm.eng.cam.ac.uk/ssme/documents/080428ssi_us_letter.pdf. Accessed 19 Sept. 2009.

Karmi, R. and Kaner, M. (2007). Integration of a Service Taxonomy. The TRIZ Journal, October, http://www.trizjournal.com/archives/2007/10/04/. Accessed 19 Sept. 2009.

Kotler, P. \& Keller, K. (2006). Marketing Management, $12^{\text {th }}$ ed., Upper Saddle River, NJ: Prentice Hall.

Leavitt, T. (1960). Marketing Myopia. Harvard Business Review, 38(4), 45-56.

Petkov, D., \& Petkova, O. (2006). The Work System Model as a Tool for Understanding the Problem in an Introductory IS Project. Paper presented at the 23rd Information Systems Education Conference (ISECON 2006), Dallas, TX.

Rai, A \& Sambamurthy, V. (2006). Editorial Notes - The Growth of Interest in Services Management: Opportunities for Information System Scholars. Information Systems Research 17(4), 327-331.

Sampson, S.E. \& Froehle, C. M. (2006). Foundations and Implications of a Proposed Unified Services Theory. Production and Operations Management 15(2), 329-343.

Spohrer, J., Maglio, P. P., Bailey, J. and Gruhl, D. (2007). Steps Toward a Science of Service Systems. IEEE Computer, 71-77.

Spohrer, J., Vargo, S.L., Caswell, N., and Maglio, P. P. (2008). The Service System is the Basic Abstraction of Service Science. Proceedings of HICSS-41, The 41 ${ }^{\text {st }}$ Hawaii International Conference on System Sciences, Waikoloa, HI.

Springer (2008). Call for Chapters. http://www.public.asu.edu/ hdemirka/index_files/CFC_SS_Books_Springer.pdf. Accessed 19 Sept. 2009.

Truex, D.P. and Alter, S (2010). Systems Analysis for Everyone Else: Empowering Business Professionals through a Systems Analysis Method that Fits Their Needs, Proceedings of ECIS 2010, the European Conference on Information Systems, Pretoria, South Africa.

Vargo, S.L. \& Lusch, R.F. (2004b). The Four Service Marketing Myths. Journal of Service Research, 6(4), 324-335.

Vargo, S.L., \& Lusch, R.F. (2004a). Evolving to a New Dominant Logic for Marketing. Journal of Marketing, 68, 1-17.

Womack, J. P. and Jones, D.T. (2005). Lean Solutions: How Companies and Customers Can Create Value and Wealth Together. New York, NY: Free Press.

(c) Steven Alter, 2011. Subsequently edited and published as pp. 61-72 in H. Demirkan, J.C. Spohrer, and V. Krishna, The Science of Service Systems, Springer, 2011 